origin may be I am not prepared to say, but they have no counterpart among birds and with a few possible exceptions none among other vertebrates.

I may say that I do not regard them as the result of mutation as the followers of de Vries apparently do, but think it likely that they may be due to the action of immediate local environment, the exact nature of which it is practically impossible for us to detect. The extremely sedentary nature of plants, especially some groups, and the ease with which isolation may affect them would tend to emphasize the effect of local environment in producing differentiation.

In terrestrial vertebrates we find among snakes certain forms with peculiar coloration occurring as colonies here and there within the range of the species which do not conform to any definite geographic habitat, and in some fossorial or semifossorial mammals similar extremely local forms occur, as 'Geomys colonus' Bangs surrounded by the range of G. floridanus and tuza and in just the same sort of environment so far as we can see; also 'Microtus rufidorsum' Baird, which occurs in colonies within the range of $M$. pennsylvanicus.

These may be parallel cases to those exhibited in Viola, Cratogus, Aster, Panicum, etc., and their sedentary nature seems to point similarly to elements in the immediate local environment as the probable cause of their differentiation.

Acad. Nat. Sciences, Philadelphia.

\section{Witmer Stone.}

ISOLATION BY CHOICE.

To the Editor of Science: The recent discussion of isolation in ScIence reminds me of a popular article I wrote for The Outlook, emphasizing the psychic factor in evolution ${ }^{1}$ - the part that choice plays. We must, it seems to me, not forget the various factors that work together at the same time in producing species. A fish with weak eyes would naturally prefer cave life, and thus isolated breed with others similarly equipped, physically and mentally. Those that have the ${ }^{1}$ February 18, 1898. physical variation without the mental would soon feel the effect of their want of sense.

The same principle applies in protective coloration. One may easily conceive of two habitats where the protective coloration would be quite different, and it is easy to see that the survival of those sensible enough to stick to the habitat best suited to them might quickly lead to intensification both of the tendency to seek the one habitat and of the coloration that adapts them to it. Indeed sexual selection may come in. Those having a willingness to accept mates with an erratic tendency to the other habitat or less protective coloration would have progeny less liable to prosper. Thus we may easily imagine two color races, species, arising, separated by a hereditary preference for different habitats, and for mates with all the peculiarities that those habitats have produced, while yet there is no physical barrier preventing the crossing, which may indeed go on to some slight extent.

\section{Alfred C. Lane.}

LARVAL CONGER EELS ON THE LONG ISLAND COAST.

THE occurrence of larval conger eels in great abundance on the Atlantic coast has, as far as I am aware, not been recorded; accordingly the following note may be of interest.

On May 27, 1905, the 'Leptocephalus' of a conger eel appeared in great numbers at Easthampton, on the south shore of Long Island, about twenty miles from Montauk Point. They were washed up by the waves, literally, in thousands, and continued to come ashore in greater or less quantity-being especially abundant again on June 3 -for about a fortnight. It was evident that this interesting harvest was due in some measure, at least, to a local storm and change of currents, which also brought in a number of bottom formse. g., Natica and its eggs.

The larvæ were all of a uniform length of about four inches, and in a few cases appeared to be in normal condition; most, however, were found to be either dead or dying. Dr. Bashford Dean, who has seen my specimens, tells me that they are probably Leptocephalus 
conger. A larva of the same species sent to Dr. Dean by Professor Grassi, who collected it at Messina, is five inches in length.

\section{S. Quackenbush.}

\section{SHOULD OUR COLLEGES ESTABLISH SUMMER SCHOOLS?}

A NEW and important feature in the educational scheme of our colleges is the growing tendency toward the establishment of summer schools. According to the report of the Commissioner of Education there were in 1903 over 11,000 students in the summer schools of 51 of our colleges. About two thirds of these students were women; mainly teachers of secondary schools. The number of students now attending the summer schools is about one tenth as great as the total number enrolled in our colleges throughout the year, and is more than twice as great as the number studying in the graduate schools of our universities.

The growth of these summer schools in America dates from 1874 when the religious assembly at Lake Chautauqua began the summer training of Sunday-school teachers, and in 1878 this movement grew into the establishment of a general summer school, aiming to disseminate culture chiefly among those who had not enjoyed the benefit of college training. In this the Chautauqua school has achieved well-renowned success, raised the general level of intelligent appreciation, and broadened the mental horizons of thousands; thus exercising a beneficent influence upon our national life not to be overestimated.

Such a summer school as that of Chautauqua, independent of any one college but dependent in a large sense upon all, aims chiefly to broaden rather than to deepen culture, and to maintain and develop the best standards of life and thought. It teaches, above all, that lives of the highest value to civilization may be devoted to the true and the beautiful rather than to the material side of progress. Its aim differs from that of the colleges in that it is extensive rather than intensive, broad rather than precise; developing thus a higher standard of general culture, rather than training specialists for professional careers.
Of late years, however, the summer school has become an established feature of the curriculum of our colleges themselves. These summer schools of the colleges are naturally centers of culture which as such must accomplish much general good, but they often hold out a false hope to those who visit them desiring to gain precise technical knowledge. One can not accomplish in six weeks what should be done in a year of patient study accompanied by laboratory experience. The tendency of these college summer schools is to substitute superficiality for depth, and to increase rather than diminish the number of half-trained specialists with which our country is already over-burdened.

But apart from their more or less beneficial effect upon the student I wish to call attention to an evil influence they are beginning to exert upon those who teach in our colleges.

Until within a few years the college teacher looked upon his summer vacation as a season for research and broadening study; now fully one half of this once cherished period must be sacrificed to the labor of the dissemination of superficial and elementary instruction.

What can we hope from our universities if the spirit of research, which already languishes, be killed within them. The intellectual achievement of our highest schools can be measured only by the standard of productive scholarship; not by the amount but by the quality of their instruction.

Men are not machines to be loaded with knowledge at one brief period in their youth, and then to impart wisdom unchanged throughout the remainder of their days, and yet this development of the summer school in connection with the college is surely cutting down those precious hours when the teacher himself becomes a student. What more stimulating to the teacher or beneficial to the college than a vacation rightly used in research, intelligent travel or in contact with his fellow men beyond the college walls.

Correlated with the growth of the summer school system is the tendency of the college itself to maintain low salaries for its instructors, relying upon the fact that by teaching in 